\title{
25-hydroxyvitamin D concentrations before and in the first year of growth hormone treatment in relation to height velocity, IGF-1 and bone age
}

MEDICAL

UNIVERSITY

OF WARSAW
Ewelina Witkowska-Sędek, Beata Pyrżak, Magdalena Sagała, Anna Majcher, Anna Kucharska Department of Paediatrics and Endocrinology, Medical University of Warsaw

\section{Introduction:}

The start of growth hormone (rhGH) treatment in children with growth hormone deficiency (GHD) causes a significant increase in bone turnover and increases height velocity. The increase in IGF-1 concentrations during rhGH treatment is a marker of the efficiency of treatment. Bone age delay at baseline is related to GHD and is a good predictor of height velocity during treatment. A significant increase in bone turnover during rhGH treatment results in an increased demand for vitamin $\mathrm{D}$. It is important to determine proper supplementation doses of vitamin $\mathrm{D}$ in patients during catch-up growth.

\section{Aim of study:}

The aim of the study is to evaluate the correlation between IGF-1, bone age and 25-hydroxyvitamin D at baseline and in the first year of rhGH treatment, and height velocity before and during $\mathrm{rhGH}$ treatment.

\section{Material and methods:}

The study group consisted of 76 children aged 3-16 years with GHD. IGF-1 and 25-hydroxyvitamin D concentrations, bone age and anthropometric parameters were measured at baseline and during 12 months of treatment.

\section{Results:}

Vitamin D status at baseline correlated with height velocity before rhGH treatment $(p<0.05, r=0.49)$. The mean 25-hydroxyvitamin $D$ concentration at baseline was $19.57 \mathrm{ng} / \mathrm{ml}( \pm 6,19 \mathrm{SD})$ and after 12 months of rhGH treatment with vitamin $D$ supplementation it increased to $24.1 \mathrm{ng} / \mathrm{ml}( \pm 6,88 \mathrm{SD})$. A negative correlation between $\Delta 25$-hydroxyvitamin $\mathrm{D}$ and $\Delta$ IGF-1 $(p<0.05, r=-0.38)$ was found.

\section{Conclusions:}

$\Delta$ vitamin $\mathbb{D}$ vs. $\Delta$ IGF-1 $(\mathrm{p}<0,05, \mathrm{r}=-0,38)$

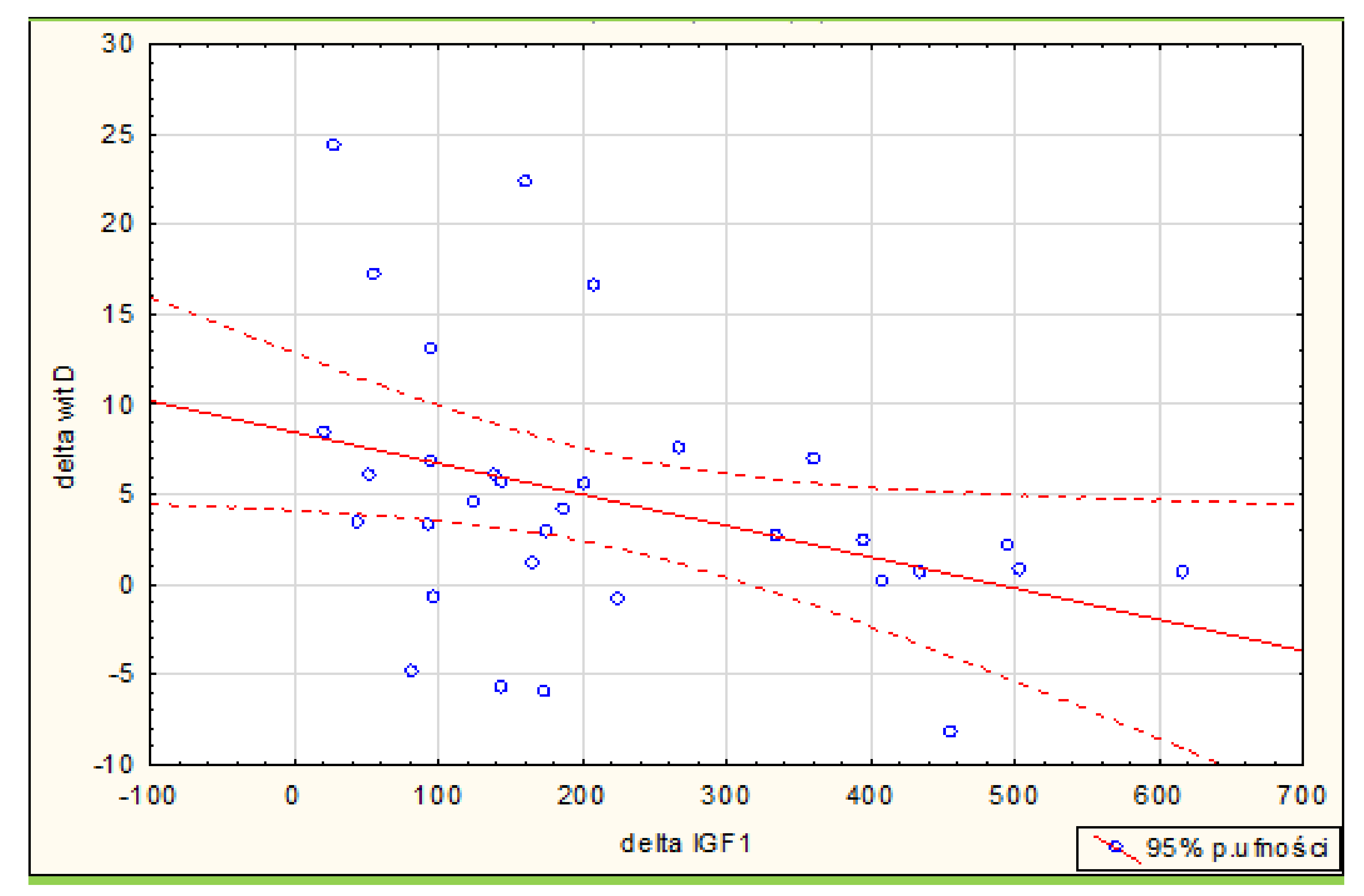

Vitamin D status is related to height velocity and adequate vitamin D supplementation is important in patients with GHD during catch-up growth, when their bone turnover is increased as a result of rhGH treatment. Determining proper supplementation doses of vitamin $D$ in such cases requires further research. 